\title{
Comparison of Anthropometric Characteristics and Blood Pressure Phenotypes between Pre-and Post-menopausal Punjabi Women
}

\author{
Badaruddoza and Manmeet Kaur Hundal \\ Department of Human Genetics, Guru Nanak Dev University, Amritsar143 005, Punjab, India
}

KEYWORDS Menopause. Blood Pressure. Anthropometric Measurement. Punjabi Women.

\begin{abstract}
The association between blood pressure phenotypes and menopause with respect to certain other metric variables were examined in a random sample of 489 pre- and 191 post-menopausal Punjabi women. Post-menopausal women had a higher blood pressure and pulse rate than pre-menopausal women $(<0.001)$. The metric measurements such as weight, BMI, waist and hip circumferences, WHR were also higher in post-menopausal women $(<0.001)$. In addition to that estimates of correlation and stepwise multiple regressions for blood pressure with other metric variables among pre- and post-menopausal women have been carried out.
\end{abstract}

\section{INTRODUCTION}

It is well established that hypertension is one of the major health burden among menopausal women. However, the etiologic factors contributing to rise of blood pressure in women after menopause are not well known. Many investigators (Colditz et al. 1987; Staessen et al. 1989; Kaur and Mogra 2006) have shown positive and significant association between menopause and blood pressure with adiposity and body measurements. However, the question that blood pressure increases independent of BMI, WHR and age following menopause has remained unanswered (Lindguist 1982; Lindguist et al. 1985). In the view of the remaining uncertainty, in the present study an attempt have been made to investigate the association between menopause and blood pressure phenotypes with respect to age, height, BMI, waist and hip circumferences, waist hip ratio and pulse rate in a random samples of Punjabi women.

\section{MATERIALS AND METHODS}

A random sample of 489 pre- and postmenopausal women was ascertained to study. Women from 20 to 55 years old are included in the present analysis. The data were collected through subsequent visit at home and worksites.

Address for correspondence:

Dr. Badaruddoza, Senior Lecturer

Department of Human Genetics, Guru Nanak Dev

University, Amritsar-143005, Punjab, INDIA

E-mail:doza13@yahoo.co.in
A self-designed questionnaire was adopted to note the menstrual status and other information of the participants. The natural menopause was defined once she has gone twelve full months with no flow at all and it is a part of women's normal ageing process. Almost all subjects are primarily vegetarian and non-alcoholic. They are living in patrilocal family system and similar household. Blood pressure of all women measured with mercury sphygmomanometer and a stethoscope in a sitting position on with the right fore arm placed horizontal on the table by following the recommendations of American Heart Association (1981). Mean arterial blood pressure (MBP) is the average blood pressure level during the cardiac cycle. MBP was simply estimated as DBP + (SBP-DBP)/3 (Perusse et al. 1989 ) and the pulse rate count over 1 minute. The anthropometric variables included height, weight, BMI, waist and hip circumferences and WHR. The waist-hip ratio (WHR) was calculated as waist circumference divided by hip circumference and the body mass index (BMI) was calculated using the standard equation: $\mathrm{BMI}=$ weight $(\mathrm{kg}) /$ height ${ }^{2}\left(\mathrm{~m}^{2}\right)$. The techniques were used for anthropometric measurements as described by Weiner and Lourie (1981) for the International Biological Programme and Singh and Bhasin (1968). The measurements were taken using standard anthropometric tools. Average of repeated measurements was taken for statistical analysis. Student's t test was used for comparing means of group. Pearson's correlation coefficient was used to determine the association of blood pressure phenotypes and metric variables with 
pre- and post-menopause women. Significant covariates of blood pressure phenotypes were identified by step-wise multiple regression model.

\section{RESULTS}

Table 1 shows means with standard deviations and comparison of different measurements of preand post-menopausal women. The means of all variables except height were significantly $(p<0.001)$ higher in post-menopausal than premenopausal women. Estimates of Pearson's correlation coefficients among age, height, weight, BMI, waist and hip circumferences, WHR and pulse rate for SBP, DBP and MBP between preand post-menopausal women are presented in table 2. Age was significant and positively associated with blood pressures (SBP, DBP and MBP) for both pre- and post-menopausal women. The correlation coefficients of waist and hip circumferences were found to be significant with DBP and MBP among pre-menopausal women and with only DBP for post-menopausal women. In multiple regression models, the standardized regression coefficient with associated standard error and the percent of variance accounted by the regressions $\left(\mathrm{R}^{2}\right)$ for blood pressure phenotypes are given in the table 3 among preand post-menopausal women. All regression coefficients except height, WHR are significant ( $\mathrm{p}<0.001$ ) for SBP and DBP among premenopausal women whereas, only weight and pulse rate for both SBP and DBP, BMI for SBP, waist and hip circumferences for DBP are found significant $(\mathrm{p}<0.05)$ among post menopausal women. However, negligible percent of variances for blood pressure phenotypes almost all other variables have been found among both groups. The results of the stepwise regression analyses are presented in table 4 . It has been seen that other than weight for SBP and BMI for DBP, age and pulse rate are the common important predictors for SBP and DBP among premenopausal women whereas, other than BMI for SBP and hip circumference for DBP, pulse rate are the significant common predictors among post menopausal women. Nonlinear trend in age is also found in the present study.

Table 1: Descriptive statistics for different characteristics of 489 pre- and 191 post-menopausal Punjabi women

\begin{tabular}{|c|c|c|c|c|}
\hline Variables & $\begin{array}{c}\text { Pre-menopausal } \\
\text { Mean } \pm S D\end{array}$ & $\begin{array}{c}\text { Post-menopausal } \\
\text { Mean } \pm S D\end{array}$ & $t$ & $P$ \\
\hline Age (years) & $28.17 \pm 6.09$ & $46.29 \pm 3.04$ & 40.27 & $<0.001$ \\
\hline Height $(\mathrm{cm})$ & $159.48 \pm 7.16$ & $158.45 \pm 6.20$ & 1.77 & NS \\
\hline Weight (kg) & $59.28 \pm 7.79$ & $64.75 \pm 9.16$ & 8.04 & $<0.001$ \\
\hline BMI $\left(\mathrm{kg} / \mathrm{m}^{2}\right)$ & $23.19 \pm 2.43$ & $25.73 \pm 3.26$ & 11.24 & $<0.001$ \\
\hline Waist Circumference $(\mathrm{cm})$ & $83.06 \pm 7.91$ & $91.29 \pm 9.96$ & 11.43 & $<0.001$ \\
\hline Hip Circumference $(\mathrm{cm})$ & $97.19 \pm 10.24$ & $105.39 \pm 9.84$ & 9.62 & $<0.001$ \\
\hline WHR & $0.85 \pm 0.04$ & $0.86 \pm 0.03$ & 3.12 & $<0.001$ \\
\hline $\mathrm{SBP}(\mathrm{mmHg})$ & $123.33 \pm 11.06$ & $146.09 \pm 23.77$ & 17.23 & $<0.001$ \\
\hline $\mathrm{DBP}(\mathrm{mmHg})$ & $79.62 \pm 7.44$ & $88.32 \pm 7.72$ & 13.81 & $<0.001$ \\
\hline MBP (mmHg) & $94.22 \pm 7.81$ & $107.67 \pm 11.75$ & 17.69 & $<0.001$ \\
\hline Pulse Rate & $81.73 \pm 7.39$ & $86.89 \pm 7.58$ & 8.32 & $<0.001$ \\
\hline
\end{tabular}

Table 2: Comparison of Pearson's correlation coefficients for blood pressure with other metric variables among pre- and post- menopausal Punjabi women

\begin{tabular}{|c|c|c|c|c|c|c|}
\hline \multirow[t]{2}{*}{ Variables } & \multicolumn{3}{|c|}{ Pre- menopausal women $(n=489)$} & \multicolumn{3}{|c|}{ Post-menopausal women $(n=191)$} \\
\hline & $S B P$ & $D B P$ & $M B P$ & $S B P$ & $D B P$ & $M B P$ \\
\hline Age (years) & 0.078 & $0.354 * *$ & $0.414 * *$ & 0.078 & 0.017 & 0.060 \\
\hline Height $(\mathrm{cm})$ & 0.061 & 0.056 & 0.063 & 0.061 & 0.040 & 0.053 \\
\hline Weight (kg) & $0.178 *$ & $0.241 * *$ & $0.316 * *$ & $0.178 *$ & $0.152 *$ & $0.202 * *$ \\
\hline BMI $\left(\mathrm{kg} / \mathrm{m}^{2}\right)$ & $0.170 *$ & $0.252 * *$ & $0.324 * *$ & $0.170 *$ & $0.156^{*}$ & $0.204 * *$ \\
\hline Waist circumference $(\mathrm{cm})$ & 0.090 & $0.235^{*} *$ & $0.297 * *$ & 0.090 & $0.148 *$ & 0.133 \\
\hline Hip circumference $(\mathrm{cm})$ & 0.117 & $0.207 * *$ & $0.270 * *$ & 0.117 & $0.176 *$ & $0.167 *$ \\
\hline WHR & 0.005 & -0.011 & -0.018 & 0.005 & 0.009 & 0.004 \\
\hline Pulse Rate & $0.459 * *$ & $0.482 * *$ & $0.514 * *$ & $0.459 * *$ & $0.426 * *$ & $0.494 * *$ \\
\hline
\end{tabular}

**Correlation is significant at the 0.01 level (2-tailed)

* Correlation is significant at the 0.05 level (2-tailed). 

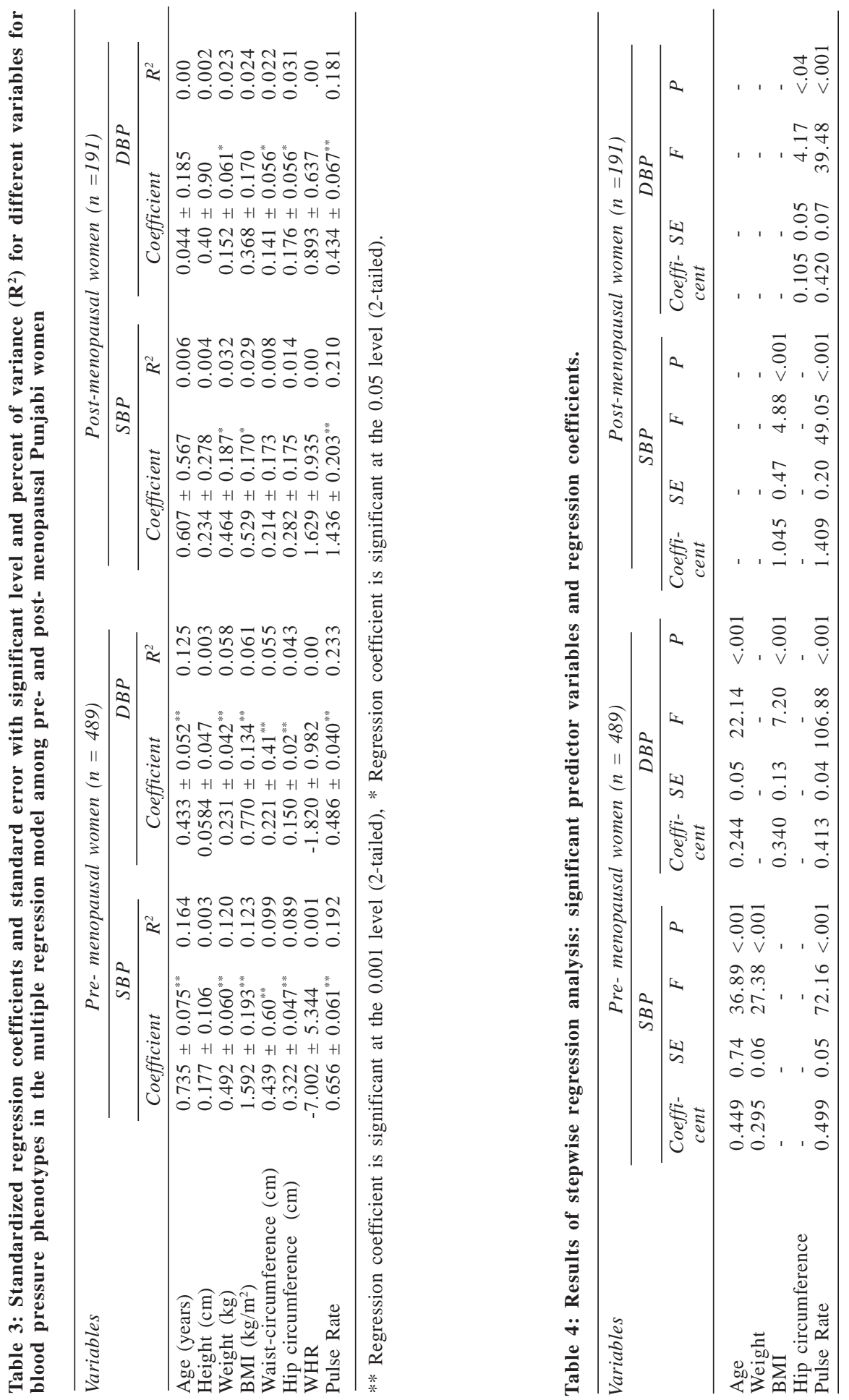


\section{DISCUSSION}

The present study has shown that the general level of blood pressure is significantly higher in post-menopausal women. The increment proportion is more pronounced on SBP than DBP. The significant effects of menopause on blood pressure have been found in many other studies (Staessen et al. 1989; Pelt et al. 2001; Garauet 2002; Sipila 2003; Skrzypezak and Szwed 2005; Kaur and Mogra 2006). The results have indicated women with higher BMI and WHR would have more chances of having cardiovascular disease after menopause. A significant increasing trend was observed for pulse rate in post-menopausal women. Many studies have found that body mass index, WHR and several anthropometric measurements were significantly higher in post-menopausal than in pre-menopausal women (Pasquali et al. 1994; Perry et al. 1997; Azizi et al. 2005; Skrzypezak and Szwed 2005; Yannakoulia et al. 2007). In general, age is found to have a significant effect on blood pressure (Majumder 1990; Badaruddoza and Afzal 1999, 2000). It may however, be pointed out that in the present study, in multiple regression model age is found to be significant with SBP and DBP among premenopausal women but not in post-menopausal women. Furthermore, stepwise multiple regression analysis results also showed that age did not significantly add to the ability of the equation to predict blood pressure in post-menopausal women. Therefore, the trend of increasing of blood pressure in the menopausal transition may be associated with higher concentration of cholesterol and triglyceride (Graff-Iversen et al. 2008; Lopez et al. 2008). The data from the present study demonstrated that the variables such as age, height, weight, waist and hip circumferences were not found to be significantly associated with increase of blood pressure among postmenopausal women. The stepwise regression analysis of the current study demonstrate the possible confounding effects of age, weight and pulse rate on blood pressure among premenopausal women, whereas, only hip circumference and pulse rate have significant effects on blood pressure among postmenopausal women. Therefore, the significant development of blood pressure or body weight is may not be associated with menopausal status (Graff-Iversen et al. 2008). However, the report suggested that increasing of blood pressure in menopause with age is due to the stiffness of the arteries (Staessen et al. 1989). This may be a one of the confounding factors in general population. Hence, the reasons responsible for increasing of blood pressure in post-menopausal women are multi-factorial and complex interrelated. Hence the findings of the present study are in agreement with the hypothesis that the drop of female sex steroids and increase of androgen after menopause affect the balance between different vasoactive hormones in the female body (Sundsfjord et al. 1972; M'Buyamba-Kabagu et al. 1885). This may lead to increase blood pressure with menopause.

\section{REFERENCES}

American Heart Association 1981.Report of subcommittee of post graduate education committee recommendations for human blood pressure determination of sphygmomanometer. Circulation, 64: 510A-509B.

Azizi F, Esmaillzadeh A, Mirmiran P, Ainy E 2005. Is there an independent association between waist-tohip ratio and cardiovascular risk factors in overweight and obese women? Int J Cardiol, 101: $39-46$.

Badaruddoza, Afzal M 1999. Age specific difference in blood pressure among inbred and non-inbred North Indian Children. J Biosci, 24 : 177-184.

Badaruddoza, Afzal M 2000. Trend of blood pressure in North Indian Children. Ind J Physiol Pharmacol, 44: 304-310.

Colditz GA, Willett WC, Stampfer MJ, Rosner B, Speizer FE, Hennekens CH 1987. Menopause and the risk of coronary heart disease in women. $N$ Engl $\mathrm{J} \mathrm{Med,}$ 316: 1105-1110.

Garauet M 2002. Body fat distribution in pre- and postmenopausal women: metabolic and anthropometric variables. J Nutr, 6: 123-126.

Graff-Iversen S, Thella DS, Hammar N 2008. Serum lipid, blood pressure and body weight around the age of the menopause. Eur J Cardiovasc Prev Rehabil, 15:83-88.

Kaur K, Mogra R 2006. Association of body mass index, body fat and hypertension among post-menopausal women. J Hum Ecol, 20:171-175.

Lindquist O 1982. Intra-individual changes of blood pressure, serum lipids and body weight in relation to menstrual status: results from a prospective population study in Goteborg, Sweden. Prev Med, 11: 162-172.

Lindquist O, Bengtsson C, Lapidus L 1985. Relationships between the menopause and risk factors for ischaemic heart disease. Acta Obstet Gynecol Scand, 130: 4347.

Lopez EP, Rice C, Weddle DO, Rahill GJ 2008. The relationship among cardiovascular risk factors, diet patterns, alcohol consumption, and ethnicity among women aged 50 years and older. J Am Diet Assoc, 108: $248-256$. 
Majumder PP, Bhattacharya SK, Mukherjee BN, Rao DC 1990 Genetic epidemiological study of blood pressure in a sedentary rural agricultural population of West Bengal, India. Am J Phys Anthropol, 81: 563-572.

M'Buyamba-Kabangu JR, Lijnen P, Fagard R et al. 1985. Erythrocyle concentrations and transmembrane fluxes of sodium and potassium and biochemical measurements during the menstrual cycle in normal women. Am J Obstet Gynecol, 151:687-693.

Pasquali R, Casimirri F, Labate AM, Tortelli O, Pascal G, Anconetani B, Gatto MR, Flamia R, Capelli M, Barbara L 1994. Body weight, fat distribution and menopausal status in women. The VMH collaborative group. Int J Obes Relat Metab Disord, 18: 614-621.

Pelt RE, Evans EM, Schechtman KB, Ehrani A, Kohrt WM 2001. Waist circumference Vs body mass index for prediction of disease risk in post menopausal women. Int J Obes, 25: 1183-1188.

Perry AC, Applegate EB, Allison ML, Miller PC, Signorile JF 1997. Relation between anthropometric measures of fat distribution and cardiovascular risk factors in overweight pre- and post-menopausal women. Am J Clin Nutr, 66: 829-836.

Perusse L, Rice T, Bouchard C, Vogler GP, Rao DC 1989. Cardiovascular risk factors in a French Canadian
Population: Resolution of genetic and familial environmental effects on blood pressure by using extensive information on environmental correlates. Am J Hum Genet, 45: 240-251.

Singh IP, Bhasin MK 1968. Anthropometry. Delhi: Kamla Raj Enterprises.

Sipila S 2003. Body composition and muscle performance during menopause. J End Invest, 26: 893-901.

Skrypezak M, Szwed A 2005. Assessment of the body mass index and selected physiological parameters in pre- and post-menopausal women. Homo, 56: 141-152.

Staessen J, Bulpitt CJ, Fagard R, Lijnen P, Amery A 1989. The influence of menopause on blood pressure. $J$ Hum Hyperten, 3: 427-433.

Sundsfjord JA and Aakvaag A 1972. Plasma renin activity, plasma renin substrate and urinary aldoster-one excretion in the menstrual cycle in relation to the concentration of progestration and oestrogens in the plasma. Acta Endocrinol, 71: 519-525.

Weiner JS, Lourie JA 1981. Practical Human Biology. London: Academic Press.

Yannakoulia M, Melistas L, Solomou E, Yiannakouris N 2007. Association of eating frequency with body fatness in pre- and post- menopausal women. Obesity, 15: $100-106$. 